\title{
Operant conditioning of head turning for visual reinforcement in three-month infants '
}

CATHRYN A. LeVISON AND PETER K. LeVISON

INSTITUTE FOR BEHAVIORAL RESEARCH, SILVER SPRING, MARYLAND

Differential conditioning of head turning for visual stimulation was demonstrated for three-month-old infants.

In his pioneering work, Papousek (1959) conditioned head turning for milk reinforcement in young infants. "Social" responses of the experimenter have also been used as reinforcers in infant conditioning studies (e.g., Brackbill, 1958). Experiments which demonstrate differential ocular orientation to visual stimuli, even in neonatal infants (e.g., Hershenson, 1964), suggest that nonsocial visual stimulation may be reinforcing for the young infant. Recently, Siqueland (1966) obtained acquisition and conditioned suppression of high amplitude sucking in four-month-old infants, using visual stimuli as reinforcers. The present study examines the effects of various patterns of visual stimulation as reinforcement for differential headturning responses in three-month-old infants.

\section{Subjects}

METHOD

Ss were 26 infants with a mean age of 83 days. All Ss were brought to the laboratory by their mothers in response to a mail request. Sessions were arranged for hours when then infants would be well rested and recently fed. Seven additional So were excluded from the data analysis for the following reasons: crying, $\mathrm{N}=1$; too sleepy, $\mathrm{N}=4$; unable to be diverted from watching its own hands, $N=2$.

Procedure

In a preliminary study with pilot Ss, a head harness was attached to the infant, providing automatic recording and reinforcement of head turns. However, attaching the device to its head often resulted in an emotional disruption to the $S$. Therefore, the procedure was modified. The infant was seated in the mother's lap 16 in. from a large panel containing a rear-projection screen. The $E$ observed the infant through a small hole in the panel under the center of the screen in the midline plane of the baby's head. A detectable deviation of S's head laterally from the midline was recorded as a head turn by the observer, who pressed one of two buttons, depending upon the direction of the turn. If the direction was appropriate for the experimental period, a visual reinforcement was automatically presented for $3 \mathrm{sec}$. There were no programmed consequences for inappropriate turns. Return of the head to the midline position was required before a successive lateral movement was recorded as a response. The reinforcing stimuli included an assortment of circles, triangles, checker boards, bull's-eyes, stripes, color patches, and abstract draw- ings, projected from the rear onto a 4.75 in. $8 q$. area by a Kodak Carousel 800 . The projector advanced after every reinforcement. A small light which, when operated, blinked at $0.3 \mathrm{sec}$ intervals, was positioned on either side of the screen, $14 \mathrm{in}$. from the mid point. Experimental periods, reinforcement presentations, and head turns were recorded on an Esterline Angus Event Recorder. Infants were permitted to use pacifiers. The mother was given a brief set of instructions-not to speak to the infant or to move during the experimental sequence except to return the pacifier to the infant's mouth if it was dropped.

Two groups were constituted. Group RL ( $N=15)$ was first reinforced for right head turns, then, after extinction, for left head turns; Group LR $(N=11)$ received left turn reinforcement first and right reinforcement second. In order to achieve relatively rapid conditioning and to keep the durations of the conditioning periods comparable among $\mathrm{Ss}$, at the start of a reinforcement period a blinking light was operated on the side to which the infant was required to turn. This stimulus almost invariably elicited the appropriate head turn, which was immediately followed by the projection of a stimulus pattern onto the screen. The blinking light was terminated after three appropriate head turns were emitted. The basic sequence for each session was as follows: (a) operant level of head turning ( $30 \mathrm{sec})$; (b) first reinforcement period -reinforcement of head turns to a specified side (1 min); (c) first extinction period (30 sec); (d) second reinforcement period-relnforcement of head turns to the opposite side (1 $\mathrm{min})$; (e) second extinction period $(30 \mathrm{sec})$. Reinforcement contingencies, stimulus duration and change, and experimental sequences were automatically programmed with conventional relay equipment. Observer rellability was obtained by sampling during the operant level and extinction periods. The Spearman rank correlation coefficient between two observers was .98 .

\section{RESULTS}

The results for the two groups are summarized in Fig. 1. In order to exclude head turn responses elicited by the blinking light, only the last $30 \mathrm{sec}$ of each reinforcement period were included in the data analysis. In the only two instances in which the $S$ falled to complete three head turns in the first $30 \mathrm{sec}$, the elicited responses were not included in the analysis. The Wilcoxon matched pairs signed-ranks test was used to compare response frequencies between experimental periods. Two-tailed tests were used in all cases; $p \leq .05$ was accepted as a significant differ- 


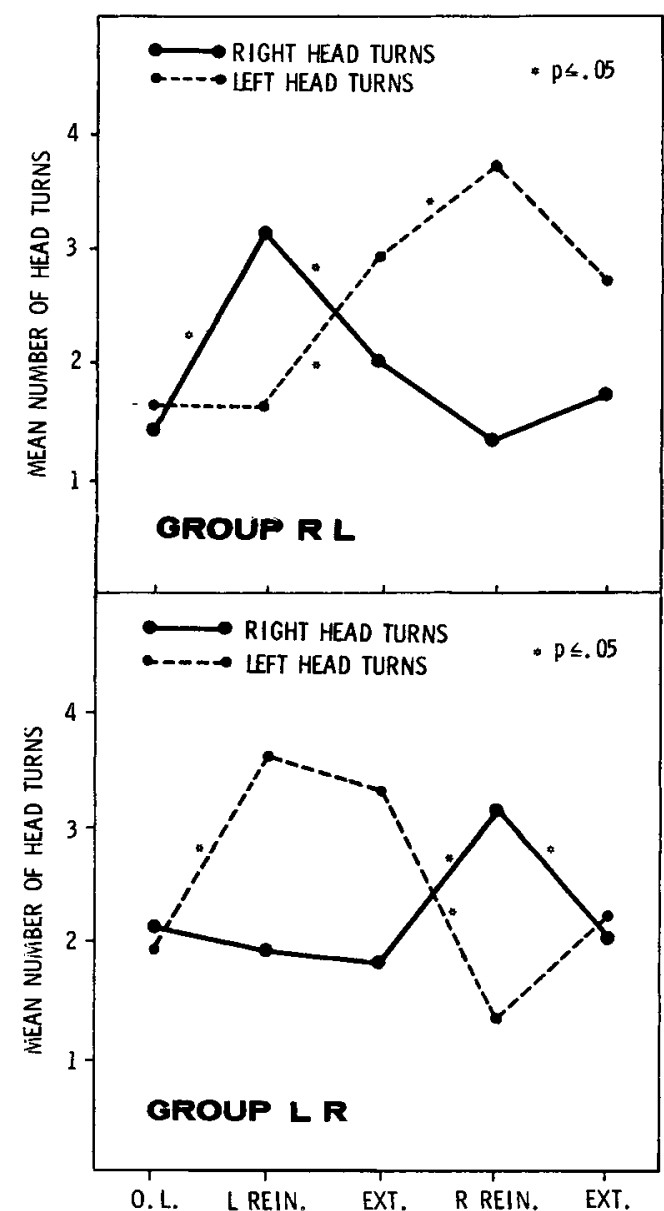

Fig. 1. Mean head tuming responses for successive $30 \mathrm{sec}$ intervals, excluding elicitation periods.

ence for all tests. For both RL and LR groups, the differences between the number of right and left head turns was significant for both reinforcement periods, and not significant for the three nonreinforcement periods.

\section{RL Group}

Right head turning responses. A significant increase in responses from the operant level to the right reinforcement period was followed by a significant decrease in the first extinction period. Changes from first extinction to left reinforcement, and left reinforcement to second extinction were nonsignificant.

Left head tuming responses. No significant changed occurred between operant level and right reinforcement. There was a significant increase from right reinforcement to first extinction, but the increase from first extinction to left reinforcement was also significant. The decrease from left reinforcement to second extinction was nonsignificant.

\section{LR Group}

Right head tuming responses. Differences in response frequencies between operant level and left reinforcement, and left reinforcement and first extinction were nonsignificant. Right head turns increased significantly from first extinction to right reinforcement, and decreased significantly from right reinforcement to second extinction. An increase from the operant level to the right reinforcement period was also significant.

Left head turning responses. A significant increase from operant level to left reinforcement was followed by a nonsignificant decrease from left reinforcement to first extinction. The decrease from first extinction to right reinforcement was significant. The change from right reinforcement to second extinction was nonsignificant.

\section{Discussion}

The results demonstrate that rapid conditioning of directional head turning, extinction, and conditioning of a response reversal can be obtained in human infants using visual stimulus patterns as reinforcing stimuli. However, the extinction results were somewhat equivocal. Decreases in the previously reinforced direction of head turning occurred for all extinction periods, suggesting the relevance of the visual stimuli for maintaining the behavior; however, the decreases following left head-turn conditioning did not reach significance within the $30-\mathrm{sec}$ extinction periods.

The relative strength of left head turning was unexpected, particularly in view of Siqueland's results (1964) showing significant preferences for right head turning in his operant level period.

Informal observations showed marked individual differences in emotional reactivity among individuals under the experimental conditions. In particular, the responses to extinction were diverse, ranging from placidity to crying during every extinction period.

Finally, the relatively low $S$ loss due to emotional disturbances elicited by the experimental situation suggests the usefulness of techniques which reduce the necessity for long experimental periods and for attaching unfamiliar mechanical devices to the infant.

\section{References}

Brackbill, Yvonne. Extinction of the smiling response in infants as a function of reinforcement schedule. Child Develpm., 1958, $29,115-124$.

Hershenson, M. Visual discrimination in the human newborn. $J$. comp. physiol. Psychol., 1964, 58, 270-276.

Papousek, H. A method of studying conditioned food reflexes in young children up to the age of six months. Pavlov Journal of Higher Nervous Activity, 1959, 9, 136-140.

Siqueland, E. R. Operant conditioning of head turning in fourmonth infants. Psychon. Sci., 1964, 1, 223-224.

Siqueland, E. R. Conditioned sucking and visual reinforcers with human infants. Unpublished paper, 1966.

\section{Note}

1. The research was supported in part by PHS Grant No. 8D 0160501 from the Department of Health, Education and Welfare. The assistance of Patricia Smith and H. Paul Norton is gratefully acknowledged. 